\title{
Reduced efficacy of marine cloud brightening geoengineering due to in-plume aerosol coagulation: parameterization and global implications
}

\author{
G. S. Stuart ${ }^{1}$, R. G. Stevens ${ }^{1}$, A.-I. Partanen ${ }^{3}$, A. K. L. Jenkins ${ }^{2}$, H. Korhonen ${ }^{3}$, P. M. Forster ${ }^{2}$, D. V. Spracklen ${ }^{2}$, and \\ J. R. Pierce P $^{1,4}$ \\ ${ }^{1}$ Physics and Atmospheric Science, Dalhousie University, Halifax, NS, Canada \\ ${ }^{2}$ School of Earth and Environment, University of Leeds, Leeds, UK \\ ${ }^{3}$ Kuopio Unit, Finnish Meteorological Institute, Kuopio, Finland \\ ${ }^{4}$ Department of Atmospheric Science, Colorado State University, Fort Collins, CO, USA
}

Correspondence to: R. G. Stevens (rgsteven@dal.ca)

Received: 7 June 2013 - Published in Atmos. Chem. Phys. Discuss.: 12 July 2013

Revised: 25 September 2013 - Accepted: 26 September 2013 - Published: 25 October 2013

\begin{abstract}
The intentional enhancement of cloud albedo via controlled sea-spray injection from ships (marine cloud brightening) has been proposed as a possible method to control anthropogenic global warming; however, there remains significant uncertainty in the efficacy of this method due to, amongst other factors, uncertainties in aerosol and cloud microphysics. A major assumption used in recent cloud- and climate-modeling studies is that all sea spray was emitted uniformly into some oceanic grid boxes, and thus these studies did not account for subgrid aerosol coagulation within the sea-spray plumes. We explore the evolution of these seasalt plumes using a multi-shelled Gaussian plume model with size-resolved aerosol coagulation. We determine how the final number of particles depends on meteorological conditions, including wind speed and boundary-layer stability, as well as the emission rate and size distribution of aerosol emitted. Under previously proposed injection rates and typical marine conditions, we find that the number of aerosol particles is reduced by over $50 \%$, but this reduction varies from under $10 \%$ to over $90 \%$ depending on the conditions. We provide a computationally efficient parameterization for cloud-resolving and global-scale models to account for subgrid-scale coagulation, and we implement this parameterization in a global-scale aerosol-climate model. While designed to address subgrid-scale coagulation of sea-salt particles, the parameterization is generally applicable for coagulation of subgrid-scale aerosol from point sources. We find
\end{abstract}

that accounting for this subgrid-scale coagulation reduces cloud droplet number concentrations by $46 \%$ over emission regions, and reduces the global mean radiative flux perturbation from $-1.5 \mathrm{~W} \mathrm{~m}^{-2}$ to $-0.8 \mathrm{~W} \mathrm{~m}^{-2}$.

\section{Introduction}

Anthropogenic greenhouse-gas emission rates are increasing (Forster et al., 2007), and it appears to be unlikely that drastic reductions in these rates will take place in the near future (Rosa and Deitz, 2012). Geoengineering, the deliberate manipulation of the earth's climate, provides possible but imperfect methods of slowing the global warming associated with the anthropogenic greenhouse gases (Royal Society, 2009). Latham (1990) proposed a method of geoengineering, commonly referred to as marine cloud brightening, in which the earth's reflectivity (albedo) is increased by adding cloud condensation nuclei $(\mathrm{CCN})$ to the marine atmosphere through emissions of sea-salt particles from specially designed ships. These additional CCN increase the number of cloud droplets and potentially increase cloud albedo (Twomey, 1974) and lifetime (Albrecht, 1989) via the aerosol indirect effects. This method of intentional enhancement of cloud albedo has been well detailed in Salter et al. (2008). Salter et al. (2008) estimates that "the cancellation of $3.7 \mathrm{~W} \mathrm{~m}^{-2}$ associated with a doubling of pre-industrial $\mathrm{CO}_{2}$ could come from a working 
fleet of approximately 1500 (ships)". They also approximate that each ship will cost "between $£ 1$ and $£ 2$ million each". These claims offer the possibility of a relatively affordable means to reverse some of the effects of global warming, which has spurred many studies using cloud models (Bower et al., 2006), cloud-resolving models (Jenkins et al., 2013; Wang et al., 2011) and global climate models (Alterskjær et al., 2012; Alterskjær and Kristjánsson, 2013; Bala et al., 2011; Jones et al., 2009; Korhonen et al., 2010; Partanen et al., 2012; Pringle et al., 2012; Rasch et al., 2009) to test the efficacy and unforeseen consequences of this geoengineering method, which may greatly increase the overall costs of this method.

All of the previous studies that estimate the efficacy of this geoengineering method did not account for the effect of aerosol particle coagulation near the source. With the global models, aerosol processing was either not accounted for (Bala et al., 2011; Jones et al., 2009; Rasch et al., 2009) or in the cases that it was (Korhonen et al., 2010; Partanen et al., 2012; Pringle et al. 2012), the coarse grid resolution (on the order of hundreds of kilometers) prevents these effects from being resolved. Cloud-resolving models have simulated plume emissions at horizontal scales of $300 \mathrm{~m}$ (Jenkins et al., 2013; Wang et al., 2011). While the inclusion of aerosol processing (Jenkins et al., 2013) will capture some aerosol coagulation within these plumes, the resolution is still too coarse to capture the high aerosol concentrations that would occur close to the proposed $2.4 \mathrm{~m}$ diameter emission source. Because coagulation rates scale with the square of particle concentrations, coagulation will occur most quickly in the initial, dense plume. This coagulation may be important in reducing the number of potential $\mathrm{CCN}$ that reach the cloud and has not yet been treated in models. Thus, the efficacy of prior estimates of sea-salt geoengineering may have been overpredicted due to the lack of these in-plume coagulation effects.

We explore the evolution of the sea-salt size distribution in these emission plumes using a multi-shelled Gaussian plume model with size-resolved aerosol coagulation. The influence of the emission rate and the emitted size distribution as well as local atmospheric conditions (wind speed and boundarylayer stability) and the stack radius on the final number and size of particles is determined using this model. We use the results of the plume model to create a computationally efficient parameterization of the loss of particle number by coagulation in plumes for cloud-resolving and global models. Although this parameterization has been designed with seasalt aerosol emitted for geoengineering purposes in mind, it is generally applicable to point sources of aerosol. We then implement the parameterization in a global-scale aerosolclimate model, and show the effect on predictions of marine cloud brightening efficacy.

We describe the Gaussian plume model used for this study, a high-resolution large-eddy simulation model used for evaluation of the Gaussian plume model, and the global model in Sect. 2. The case descriptions are shown in Sect. 3. We

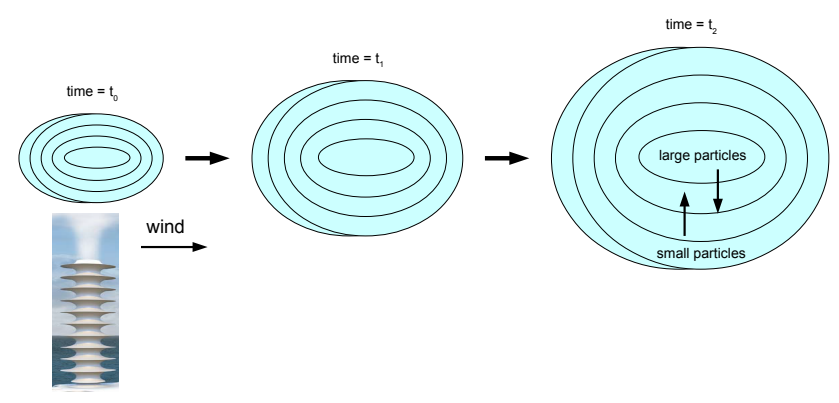

Fig. 1. Schematic of the Gaussian plume model. The shells expand with time due to dilution. Coagulation proceeds more quickly in the inner shells, due to higher particle concentrations, and thus there is a net flux of small particles to the inner shells and large particles to the outer shells.

introduce the form of the parameterization in Sect. 4. We evaluate the parameterization and show the sensitivities to each variable in Sect. 5. We describe the global model experimental design and show the global model results in Sect. 6. Finally, we present our conclusions in Sect. 7.

\section{Model descriptions}

\subsection{Gaussian plume model}

We use a multi-shelled Gaussian plume model to assess the effects of coagulation on the sea-spray particle size distribution (Fig. 1). The design of the model follows Lazaridis et al. (2001). The model follows the mean wind speed as a Lagrangian parcel, and the 10 shells expand with distance from the source following the expansion of a Gaussian plume (Seinfeld and Pandis, 2006). The outsides of the 10 shells represent $0.3,0.6,0.9,1.2,1.5,1.8,2.1,2.4,2.7$ and 3.0 standard deviations of the particle number concentration across the Gaussian plume. The expansion of the shells with distance uses the method of Klug (1969) with the plume expanding more quickly under unstable conditions than stable conditions (stability classes discussed in Sect. 3). The initial 1-standard-deviation plume width is set equal to the diameter of the emission stack ( $2.4 \mathrm{~m}$ as a base-case approximation but varied later). The depth of the shells (in the direction of the wind), set arbitrarily to $10 \mathrm{~m}$, is used only to calculate total particle number from the particle concentrations and has no effect on the model results. We assume that coagulation occurs through Brownian coagulation only, and we calculate the coagulation kernel using the method of Fuchs (1964). Similar plume models have shown good agreement with field measurements downwind from power plants (Hudischewsky and Seigneur, 1989; Lazaridis et al., 2001), and have been used to predict plume visibility (Seigneur et al., 1997) and to study mercury speciation, transport and deposition (Lohman et al., 2006). 
The model tracks the aerosol size distribution using 100 size bins, spaced logarithmically between $10 \mathrm{~nm}$ and $10 \mu \mathrm{m}$ in wet diameter (at $80 \%$ relative humidity (RH)). The plume is initialized at the beginning of the simulation with the total number of particles that would be emitted into a box that is $10 \mathrm{~m}$ deep (and the width of the stack diameter) if the box is traveling at the same speed as the wind. The higher particle concentrations near the center of the plume cause faster coagulation near the center and thus a difference in the shape of the size distribution between the center and outside of the plume. While inert species do not need to be transferred between the shells of the plume (the expansion of the shells accounts for diffusion), this enhanced coagulation near the middle of the plume requires us to account for a net diffusion of big particles from the center shells outward and a net diffusion of smaller particles from outer shells inward (Fig. 1). To calculate the rate of this net diffusion between shells, we normalize the size-dependent aerosol concentrations by an inert tracer (which allows us to determine if coagulation has caused an increase or decrease in the number of aerosols in the size bin) and then calculate the diffusion of the normalized values using Fick's law. The model uses a varying time step to speed up calculation during periods of low coagulation.

We represent the emitted aerosols using a single lognormal mode or a single monodisperse size. We vary the numbermedian diameter and the width of the mode to determine the effect on the fraction of particles remaining after in-plume coagulation. We represent the background marine aerosol using the two-mode lognormal distribution as described in Heintzenburg et al. (2000). However, we find that these background particles have a negligible effect on the results because the concentrations are small compared to the concentrations of emitted sea spray. Increasing the background concentrations by a factor of 10 decreased the number of remaining emitted particles by less than $0.001 \%$ under the base-case emission conditions described shortly.

Condensable sulfate and organic vapors are not currently included in the model. The concentrations of sea-spray aerosols in these plumes will be sufficiently large compared to the concentrations of secondary vapors during the short time that is being simulated that the effects of condensation on the aerosol size distributions will be insignificant.

Our model has several limitations. We assume that the wet aerosol and the air reach an instant equilibrium at $80 \% \mathrm{RH}$. There are two implications of this: (1) the wet diameter of the particles may be different than we assume (however, we do show later that the results are less sensitive to size than other factors), and (2) the evaporation of the droplets may affect the dynamics of the plume (e.g., the plume is cooler than its surroundings and sinks) and affect the mixing rate of the plume. We assume that our plume is perfectly Gaussian. Turbulent plumes in unstable boundary layers are only Gaussian when time-averaged. An actual plume may have higher- and lower-concentration regions, and because of the quadratic relationship of the rate of coagulation with concentrations, this could cause our model to underpredict coagulation slightly in unstable boundary layers (Stevens et al., 2012). We assume that the plume can expand without bounds. An actual plume will be limited in the vertical direction by the ocean surface below and the height of the mixed layer above. The plume is unlikely to expand to the height of the mixed layer within timescales relevant to the fast plume coagulation discussed here, but reflection of the plume from the ocean surface would result in higher concentrations, causing our model to underpredict coagulation. We do not consider the initial upward velocity of the sea-spray emissions as they exit the solid stack or any possible vortex shedding (Latham et al., 2012). We will address these uncertainties in Sect. 5.

We note that the results of the model do not strongly depend on the composition of the aerosol. The Gaussian plume model, and the parameterization based upon the model, can therefore be generally applied to other point sources of aerosol, provided the above assumptions are met. Most notably, the concentrations of the aerosol must be sufficiently large relative to condensable species that the effects of condensation on the aerosol size distributions will be insignificant. In addition, because we have assumed hydrophilic aerosol at $80 \%$ relative humidity, the size of the aerosol may differ based on composition and relative humidity. This uncertainty will be discussed in Sect. 5 .

\subsection{Large-eddy simulation model}

In order to augment the Gaussian plume model results, we now briefly describe a comparative alternative modeling approach. This alternative technique follows previous largeeddy simulation (LES) modeling of marine stratocumulus cloud brightening (Jenkins et al., 2013; Jenkins and Forster, 2013) and uses the same model (WRF/Chem V3.3.1; Skamarock et al., 2008). Here, however, much higher resolutions and smaller domain sizes are used $(0.5 \mathrm{~m}$ horizontal and $\sim 1 \mathrm{~m}$ vertical), with these LES simulations having a fixed domain size of length $120 \mathrm{~m}$, width $40 \mathrm{~m}$ and approximately $60 \mathrm{~m}$ height. As such, these simulations are designed to capture the emitted aerosol plume alone, independent of wider marine boundary layer turbulence. A representation of the structure of the resulting plume is shown in Fig. 2. The emission outlet, with diameter $\sim 2.5 \mathrm{~m}$, is located $20 \mathrm{~m}$ from the boundary at a height of $\sim 20 \mathrm{~m}$. Aerosol emissions from the outlet are introduced continuously at a rate equivalent to a $30 \mathrm{~kg} \mathrm{~s}^{-1}$ sea-spray injection rate (suggested by Salter et al., 2008) into an upward flow velocity of $12 \mathrm{~m} \mathrm{~s}^{-1}$ (again suggested by Salter et al., 2008). It is assumed that for this limited domain region (close to the aerosol emission point) the dynamics resulting from this upward flow velocity would dominate over marine boundary layer turbulence. The aerosols are assumed to have a dry diameter of $200 \mathrm{~nm}$ (entered into bin three of the eight bin model), resulting in an 


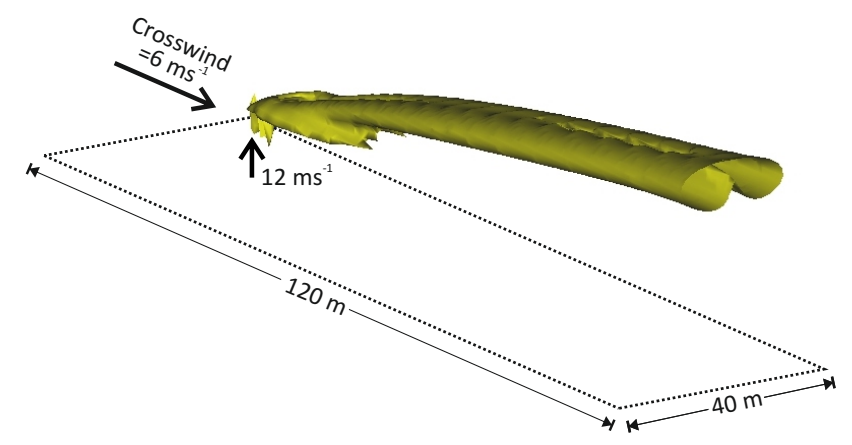

Fig. 2. The typical structure of an aerosol plume simulated within the LES model represented by an instantaneous isosurface for a given aerosol concentration during the approximately steady-state period. (The case shown is a simulation used during trials of the methodology.)

emission number flux of $1.1 \times 10^{17} \mathrm{~s}^{-1}$. The $10 \mathrm{~m}$ crosswind (assumed to comprise both ambient wind and ship velocity components) was initialized at $6 \mathrm{~m} \mathrm{~s}^{-1}$, with the boundary layer total water mixing ratio initialized at $10 \mathrm{~g} \mathrm{~kg}_{\text {dryair }}$, and potential temperature initialized at $288.3 \mathrm{~K}$. The LES model uses the eight-bin MOSAIC aerosol scheme, including Brownian coagulation (Zaveri et al., 2008), with 1.5 order 3-D turbulent kinetic energy closure scheme for subgrid turbulence. Advection is constrained by the monotonic flux limiter option (Wang et al., 2009), and surface layer physical processes are represented by the Monin-Obukhov scheme. The time step is $0.003 \mathrm{~s}(0.36 \mathrm{~s}$ for the aerosol processes), with data being output every $2 \mathrm{~s}$. The simulation was carried out for 88 model seconds. From the start of the simulation, the aerosol plume takes approximately $16 \mathrm{~s}$ to reach the domain boundary. After this time, the simulation reaches an approximate steady state whereby the mass of aerosols being emitted into the domain is approximately equal to the mass of aerosols leaving the domain. Simulations with this model suggest that despite the relatively coarse resolution for representing the $\sim 2.5 \mathrm{~m}$ outlet diameter, this model configuration successfully reproduces key dynamical features that are characteristic of an emission jet into a crosswind flow (Mahesh, 2013). These features include the formation of a counterrotating vortex pair (evident in Fig. 2), the preferential distribution of the aerosol particles at the centers of the vortices (Tu and Liu, 2012; Wen et al., 1992), and a plume trajectory in reasonable agreement with empirical data (Muppidi and Mahesh, 2005). The high-resolution LES model therefore can resolve fluid-dynamics features that cannot be resolved by a Gaussian plume model. We compare the results of the LES model with those of the Gaussian plume model in Sect. 5 .

\subsection{Global-scale aerosol-climate model}

For the global simulations to evaluate the effect of the parameterization, we used aerosol-climate model ECHAMHAMMOZ (ECHAM5.5-HAM2) (Stier et al., 2005; Zhang et al., 2012) with the same model and experiment setup as in geoengineering simulations described by Partanen et al. (2012). The aerosol microphysics module M7 (Vignati et al., 2004) describes internally and externally mixed aerosol distribution with seven log-normal modes consisting of sulfate, sea salt, organic carbon, black carbon and mineral dust. The model calculates nucleation of new particles, condensation of sulfuric acid vapor, coagulation, uptake of water, and removal of aerosols by dry deposition, sedimentation, and wet deposition.

Aerosol emissions from anthropogenic sources and biomass burning were taken from the AeroCom database (Dentener et al., 2006) for the year 2000. Dust, dimethyl sulfide, and natural sea salt emissions were calculated online as described by Zhang et al. (2012).

The cloud droplet activation was calculated online with a physically based parameterization (Abdul-Razzak and Ghan, 2000; Lohmann et al., 2007). Updraft velocity in stratiform clouds for the activation parameterization was calculated as the sum of grid-mean vertical velocity and a turbulent contribution (Lohmann and Hoose, 2009). Cloud microphysics (including both first and second indirect effects) were calculated as described by Lohmann and Hoose (2009). The combination of the model version and the cloud activation parameterization is unpublished and may differ from the official model version to be released with respect to, for example, model tuning parameters.

\section{Gaussian plume model case descriptions}

In this study, we test the sensitivity of the "fraction of particles remaining" (the final particle number divided by the initial particle number) to the wind speed $\left(v_{\mathrm{w}}\right)$, particle number emission rate $(P)$, the emission number-median dry diameter $\left(D_{\mathrm{p}}\right)$, the emission geometric standard deviation $(\sigma)$ and the emission-source radius $\left(R_{\mathrm{S}}\right)$. The maximum, minimum and base-case values are provided in Table 1 . Our base case uses particle emissions with a $D_{\mathrm{p}}$ of $200 \mathrm{~nm}$, which correspond to the size of a dry sea-spray particle obtained from an $800 \mathrm{~nm}$ seawater drop (Lewis and Schwartz, 2004) as described in Salter (2008). The emitted $\sigma$ is set arbitrarily to 1.2 in the base case. Salter (2008) describes sea-spray emissions at a total sea-water flow rate of $30 \mathrm{~kg} \mathrm{~s}^{-1}$. This flow rate, if broken up into the $200 \mathrm{~nm}$ dry diameter $(800 \mathrm{~nm}$ wet diameter) mode described above, corresponds to an aerosol number emission rate of $1.1 \times 10^{17} \mathrm{~s}^{-1}$, which we use as our base-case value for $P$. We use a base-case $v_{\mathrm{w}}$ of $8 \mathrm{~m} \mathrm{~s}^{-1}$, which corresponds to the minimum wind speed needed to obtain a sea-water flow rate of $30 \mathrm{~kg} \mathrm{~s}^{-1}$ as described in Salter 
Table 1. The variables explored in the plume modeling and the range of values used for each.

\begin{tabular}{lrrr}
\hline Variable & Minimum & Base case & Maximum \\
\hline Wind speed $\left(v_{\mathrm{W}}\right)$ & $4 \mathrm{~m} \mathrm{~s}^{-1}$ & $8 \mathrm{~m} \mathrm{~s}^{-1}$ & $20 \mathrm{~m} \mathrm{~s}^{-1}$ \\
Particle number emission rate $(P)$ & $1.1 \times 10^{16} \mathrm{~s}^{-1}$ & $1.1 \times 10^{17} \mathrm{~s}^{-1}$ & $1.1 \times 10^{18} \mathrm{~s}^{-1}$ \\
Number-median dry diameter $\left(D_{\mathrm{p}}\right)$ & $100 \mathrm{~nm}$ & $200 \mathrm{~nm}$ & $400 \mathrm{~nm}$ \\
Geometric standard deviation $(\sigma)$ & 1 (monodisperse) & 1.2 & 2 \\
Emission-source radius $\left(R_{\mathrm{S}}\right)$ & $0.6 \mathrm{~m}$ & $1.2 \mathrm{~m}$ & $2.4 \mathrm{~m}$ \\
\hline
\end{tabular}

(2008) and Korhonen et al. (2010). The minimum and maximum values in Table 1 allow us to both test the sensitivity of the fraction of particles remaining to each of the five parameters as well as allow us to create a parameterization of the fraction of particles remaining for large-scale models.

Additionally, we evaluate the fraction of particles remaining under the six Pasquill stability classes (Pasquill, 1961): A, extremely unstable; B, moderately unstable; C, slightly unstable; D, neutral; E, slightly stable; and $F$, moderately stable. Because the marine boundary layer is often close to neutral stability, our base stability is D; however, we test all conditions and build the parameterization for each.

\section{Parameterization formulation}

Using the Gaussian plume model described above, we have created a computationally efficient parameterization of the loss of particle number by coagulation in plumes for use in cloud-resolving and global models. In this section we introduce the form of the parameterization.

Turco and Yu (1997) give analytic solutions for the change in number due to coagulation for expanding plumes. They give the number of particles $N_{\mathrm{p}}$ that is asymptotically reached with time as

$N_{\mathrm{p}}=\frac{N_{\mathrm{po}} N_{T}}{N_{\mathrm{po}}+N_{T}}$,

where $N_{\text {po }}$ is the initial number of particles, and $N_{T}$ is defined for plumes that expand super-linearly with time as

$N_{T}=\frac{2 V_{\mathrm{o}}(\alpha-1)}{K_{\mathrm{c}} t_{i}}$,

where $V_{\mathrm{o}}$ is the initial volume, $t_{i}$ the time it would take the plume to expand from a point source to its initial volume given its rate of expansion, $K_{\mathrm{c}}$ the effective coagulation kernel, and $\alpha$ a parameter that dictates the rate of expansion, which is a function of the atmospheric stability. If we define $F$ as the fraction of particles remaining $\left(N_{\mathrm{p}} / N_{\mathrm{po}}\right)$, we can rearrange Eq. (1) and substitute Eq. (2) to give

$F=\frac{2 V_{\mathrm{o}}(\alpha-1)}{K_{\mathrm{c}} t_{i} N_{\mathrm{po}}-2 V_{\mathrm{o}}(\alpha-1)}$.

To simplify this further, we can divide through by $V_{\mathrm{o}}$ to get

$F=\frac{2(\alpha-1)}{K_{\mathrm{c}} t_{i} C_{\mathrm{o}}+2(\alpha-1)}$, where $C_{\mathrm{o}}$ is the initial particle concentration.

Our goal is to fit $F$ to five different parameters: wind speed $\left(v_{\mathrm{w}}\right)$, emission stack radius $\left(R_{\mathrm{S}}\right)$, particle emission rate $(P)$, particle median dry diameter $\left(D_{\mathrm{p}}\right)$, and the geometric standard deviation of the size distribution $(\sigma)$. We note that $\alpha$ depends only on the boundary-layer stability, and that we can incorporate $2(\alpha-1)$ into a constant dependent only upon the stability class. The other factors must only affect the $K_{\mathrm{c}} t_{i} C_{\mathrm{o}}$ term. We therefore choose to fit our multi-shelled Gaussian plume model data to a semi-empirical equation of the following form:

$$
F=\frac{k}{\left(\frac{v_{\mathrm{w}}}{v_{\mathrm{w} 0}}\right)^{a}\left(\frac{R_{\mathrm{S}}}{R_{\mathrm{s} 0}}\right)^{b}\left(\frac{P}{P_{0}}\right)^{c}\left(\frac{\sigma}{\sigma_{0}}\right)^{d}\left(\frac{D_{\mathrm{p}}}{D_{\mathrm{p} 0}}\right)^{e}+k},
$$

where the constants " $a$ " through " $e$ " along with $k$ are fitted parameters for each stability class, and the " 0 " subscripts denote the base case conditions (Table 1). Thus, the fraction of the particles remaining would be a function of the five parameters and the stability class, which may be provided by a cloud-resolving or global model. As a supplement, we provide Fortran code of this parameterization for use in these models.

To sample the entire parameter space to create training data for the fit of the parameterization, we have used a pseudo-random Latin hypercube (McKay, 1979) in order to choose our parameters for 1000 simulations of the multishelled Gaussian plume model for each boundary-layer stability. A Latin hypercube is a method of sampling a parameter space such that the full range of each parameter is sampled evenly, but the values of each variable are uncorrelated. Using a least-squares fitting, we calculated the best-fit values of $a, b, c, d, e$ and $k$ for the parameterization, and these values, as well as goodness-of-fit metrics, are shown in Table 2. We will discuss the best-fit values and the parameterization results in the following section.

\section{Gaussian plume model results}

As a demonstration of the coagulation within the multiple shells of the model, Fig. 3 shows the fraction of particles remaining and particle concentrations for $18000 \mathrm{~s}(5 \mathrm{~h})$ for the base case. We show the values for each shell as well as the 
Table 2. The fitted exponents and constant corresponding to Eq. (5) for each stability class as well as the root-mean-square error and correlation coefficient in the fraction of particles remaining associated with each fit. The exponents $a, b, c, d$, and $e$ correspond to the parameters $v_{\mathrm{W}}, R_{\mathrm{S}}, P, \sigma$, and $D_{\mathrm{p}}$, respectively. Stability classes: A, extremely unstable; B, moderately unstable; C, slightly unstable; D, neutral; E, slightly stable; and F, moderately stable.

\begin{tabular}{lcccccccc}
\hline Stability Class & $a$ & $b$ & $c$ & $d$ & $e$ & $k$ & Root-mean-square error & Correlation coefficient \\
\hline A & -0.84 & -0.40 & 0.51 & 0.30 & -0.13 & 1.282 & 0.046 & 0.9646 \\
B & -0.96 & -0.39 & 0.56 & 0.33 & -0.14 & 1.219 & 0.041 & 0.9761 \\
C & -1.17 & -0.36 & 0.65 & 0.37 & -0.16 & 0.969 & 0.030 & 0.9905 \\
D & -1.28 & -0.30 & 0.69 & 0.38 & -0.17 & 0.774 & 0.023 & 0.9951 \\
E & -1.34 & -0.23 & 0.72 & 0.38 & -0.18 & 0.611 & 0.018 & 0.9971 \\
F & -1.41 & -0.13 & 0.76 & 0.37 & -0.18 & 0.363 & 0.010 & 0.9990 \\
\hline
\end{tabular}
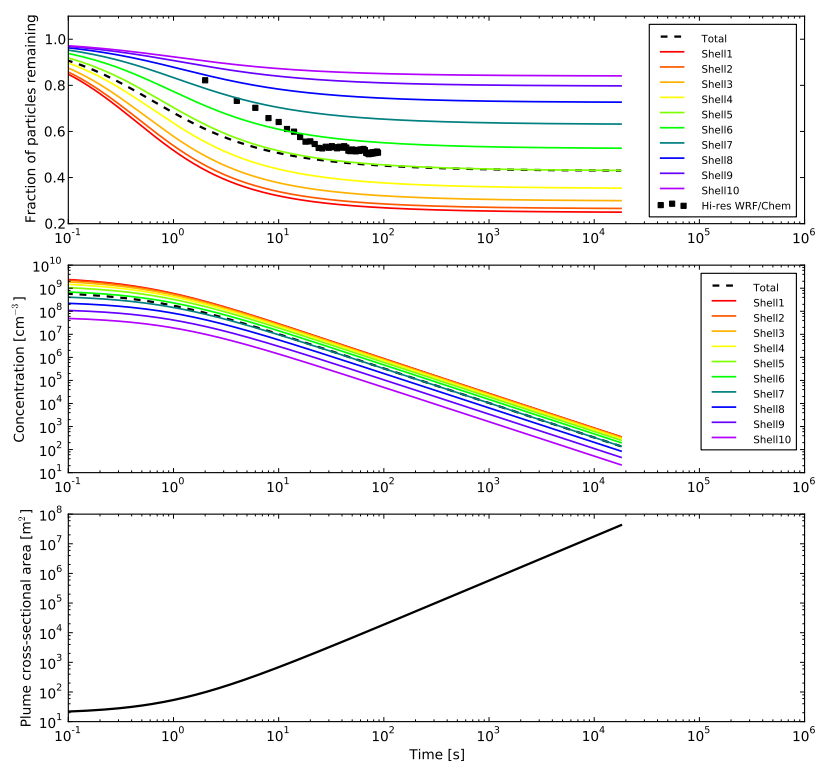

Fig. 3. The fraction of particles remaining, the concentrations, and the plume cross-sectional area are shown over time for each shell for the base case. The black dashed line shows the average across the plume, and the black square points show high-resolution results from the WRF/Chem large-eddy simulation model.

plume-scale averages. We also show the results of a highresolution LES model for comparison, described in Sect. 2. The LES model results will be discussed in the following paragraph. Particle concentrations are affected by both coagulation and plume expansion while the fraction of particles remaining is affected only by coagulation. As would be expected, the innermost shells with the highest initial particle concentrations show the largest fractional loss in particle number due to coagulation. Figure 3 shows that over $80 \%$ of coagulation occurs in the first $10 \mathrm{~s}$, which would correspond to plume spatial scales (about $10 \mathrm{~m}$ wide by $4 \mathrm{~m}$ tall for neutral stability) and distances downwind $(80 \mathrm{~m})$ that are smaller than the resolution of most cloud models. Coagulation slows and the fraction of particles remaining reaches an asymptote after about $300 \mathrm{~s}$ ( $5 \mathrm{~min}$ ). For all future simulations in this paper, we simulate $3000 \mathrm{~s}(50 \mathrm{~min})$, which will include the majority of the coagulation under all conditions. Additionally for the remainder of the paper, we will only present the overall fraction of particles remaining across all shells as this overall fraction is what is most useful for cloud and global models.

In order to evaluate the presented Gaussian plume model results, we also show the results of a high-resolution LES model, described in Sect. 2.2. We note that the values of the wind speed used in the LES model are similar but not equal to those used as the base case for the Gaussian plume model, and that the aerosols are emitted at a single monodisperse size, where they were emitted as a lognormal mode in the Gaussian plume model simulations in Fig. 3. Additionally, the Gaussian plume model simulations do not have an initial upwards velocity. In spite of the very different approach of this LES modeling technique to the Gaussian plume model, and slight disparities in initial conditions, the time series of fraction of particles remaining (Fig. 3a) show notable similarities, particularly in asymptotic behavior and limits, which gives us confidence in the results of the multi-shelled Gaussian plume model.

As discussed in Sect. 4, we used least-squares fitting to calculate the best-fit values of the exponents and the constant for the parameterization (Eq. 5) for each stability class. The exponents for the wind speed, " $a$ ", and for the stack radius, " $b$ ", are most sensitive to the stability class. In our model, both the boundary-layer stability and the wind speed are used to calculate the rate of expansion of the plume. This dependence of expansion on the two variables explains the large dependence of " $a$ " on the stability class (e.g., under unstable conditions the plume expands quickly regardless of wind speed and thus has a lower dependence on the wind speed). The plume volume expands super-linearly; as the volume of the plume increases, the rate of volume expansion also increases. The acceleration of the plume volume expansion is more pronounced under more unstable conditions, and the plume volume expansion rate is nearly constant under extremely stable conditions. As the stack radius determines the initial volume of the plume, it also determines in part the initial expansion rate of the plume, but this effect is more 


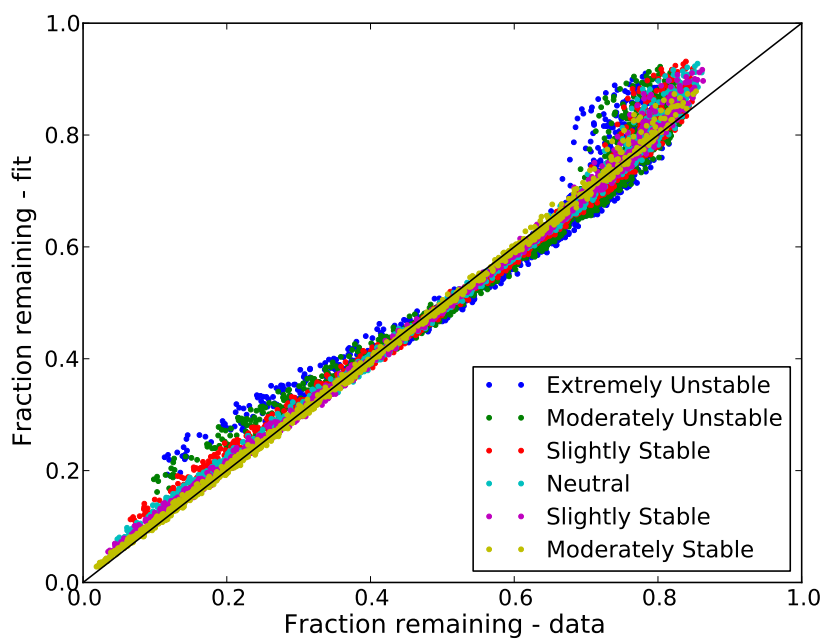

Fig. 4. The fraction of particles remaining for the parameterization (fit) compared to full Gaussian multi-shelled model results (data). The black line represents a perfect match between the fit and model.

pronounced under more unstable conditions. The " $b$ " exponent is therefore larger in magnitude for the more unstable stability classes. The exponents for variables that do not affect the expansion of the plume, such as $D_{\mathrm{p}}$ and $\sigma$, do not vary much for different stability classes.

Figure 4 shows the agreement in the fraction of particles remaining, $F$, between the fit parameterization and full multi-shelled Gaussian plume model for all stability classes. The fit tends to overestimate $F$ for some cases for both high and low values of $F$, and the overestimations are larger for more unstable stability classes. However, we note that marine stratocumulus clouds, which would be targeted with this method, are unlikely to form under unstable conditions. Overall, the agreement of the parameterization with the full multi-shelled Gaussian plume model is good with root-meansquared errors in $F$ below 0.05 for all stability classes (as low as 0.01 for the most stable case) and correlation coefficients above 0.964 for all stability classes (as high as 0.999 for the most stable case). These results justify the semi-empirical equation that we use for the parameterization based on Turco and $\mathrm{Yu}$ (1997).

Figure 5 shows the dependence of $F$ on each of the varied parameters. For each panel, one parameter is varied on the $x$ axis while the other four parameters are held fixed at their base-case values (Table 1). Each stability class is shown by the different colors, the full multi-shelled Gaussian plume model results by the solid lines, and the fit parameterization by the dashed lines. Figure 5a shows the results for varied wind speed. Increasing the wind speed greatly increases $F$ because the initial particle concentrations are lower (air spends less time passing over the stack) and the plume expands more quickly with time. As with all panels, the most stable cases show the lowest $F$ (plume expands the most slowly). In Fig. 5b, $F$ increases somewhat with the stack radius. A wider stack radius leads to lower initial particle concentrations for the same particle emission rate. Figure $5 \mathrm{c}$ shows the sensitivity to the number of particles emitted. Because coagulation goes with the square of particle number concentration, $F$ is strongly sensitive to the particle emission rates and varies from over 0.8 to under 0.1 for the ranges tested. Figure $5 \mathrm{~d}$ and e show that $F$ is not strongly sensitive to the initial particle dry diameter or width of the distribution, but they show a slight increase in $F$ with increasing diameter (due to a reduction in the self-coagulation kernel across accumulation-mode sizes, Seinfeld and Pandis, 2006) and a slight decrease in $F$ with increasing $\sigma$ (due to broader particle size distributions coagulating more quickly, Seinfeld and Pandis, 2006). We note that while the parameterization takes the median dry diameter of the particles as input, the Gaussian plume calculations used the wet diameter of the particles assuming instant equilibrium at $80 \%$ relative humidity.

There were several limitations of our modeling work discussed earlier. These involve an overestimation of particle size due to instant evaporation to $80 \% \mathrm{RH}$ equilibrium, an underestimation of the mixing due to turbulence generated by the initial upward motion of the sea-spray plume leaving the stack and vortex shedding due to the flow of air around the solid stack, an overestimation of the mixing under turbulent conditions due to the Gaussian plume assumption, as well as the reflection of the plume from the ocean surface. $F$ was not strongly sensitive to particle size (the difference between 200 and $400 \mathrm{~nm}$ dry-diameter particles was on the order of 0.05 or less), so we expect these to be the maximum errors due to the assumption of the particles instantly reaching their equilibrium size. In addition, this indicates that results of the parameterization are not strongly dependent on the assumption of $80 \%$ relative humidity or the assumption that the particles are perfectly hydrophilic. Overall, the underestimation of mixing due to the initial upward velocity of the particles and vortex shedding would lead to somewhat larger values of $F$ than predicted here (perhaps resembling lower stability classes). Jenkins and Forster (2013) found that including water with the emitted aerosols (as may occur during implementation) led to evaporation and reduced buoyancy within the plume. This caused a reduced vertical plume height but increased horizontal dispersion. As such, the particle concentrations within the plume were not significantly affected, suggesting that this effect would not significantly alter $F$. The importance of the reduced buoyancy on the subsequent transport of aerosols to the cloud is outside of the scope of the current work, and further investigation is planned. Regarding the overestimation of mixing under turbulent, unstable conditions, the marine boundary layer generally does not have strong instabilities, so this issue is likely minor. Regarding the ignoring of the ocean surface in the plume expansion, $F$ decreases most quickly close to the emission source. Generally, over $80 \%$ of the coagulation occurs in the first $10 \mathrm{~s}$. The time required for the plume to expand to the ocean surface will depend on the emission height and the stability, but for 

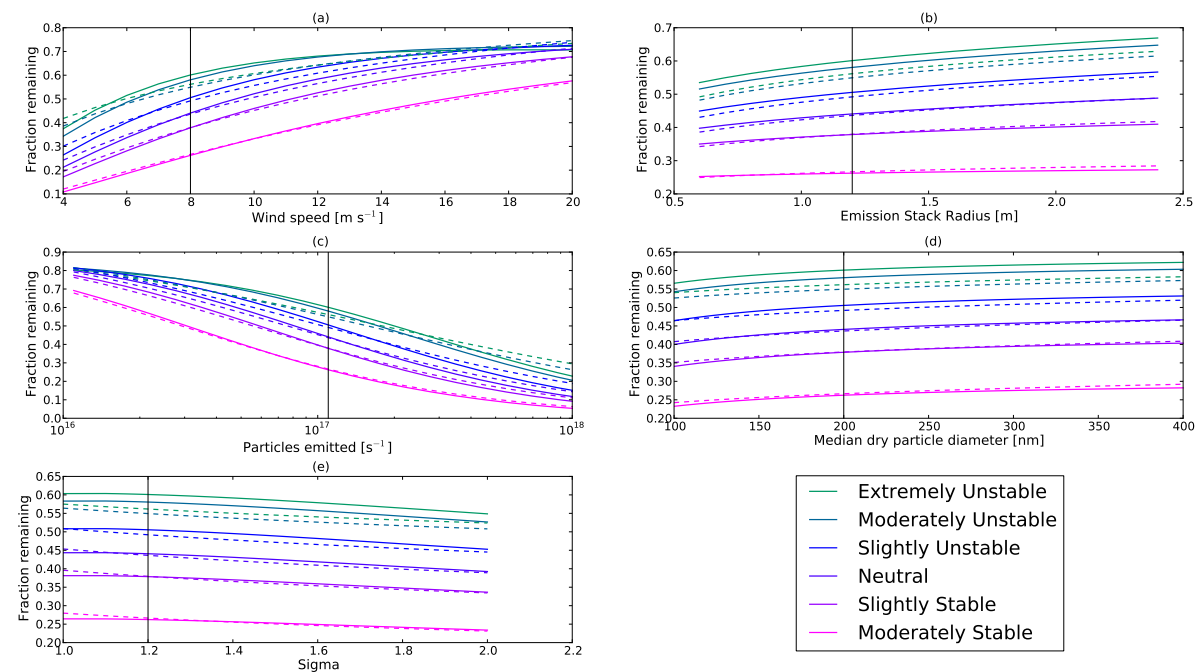

Fig. 5. The dependence of $F$ on each of the varied parameters for all stability classes. In each plot, one parameter is varied while the other four are kept at their base-case values. The full multi-shelled Gaussian plume model results are shown by the solid lines, and the fit parameterization is shown by the dashed lines. The solid black vertical lines indicate the base-case value for each parameter.

the emission heights of $20 \mathrm{~m}$ given in Salter et al. (2008) and neutral stability, the lower edge of the one-standard-deviation shell takes about $50 \mathrm{~s}$ to reach the ocean surface. We therefore expect that ignoring the ocean surface will not result in significant errors in $F$ under typical marine conditions.

Many cloud and large-eddy simulation models are able to resolve time steps shorter than the time required for the fraction of particles remaining to asymptote to a constant value, and it therefore may seem counter-intuitive to use a parameterization that accounts for $50 \mathrm{~min}$ of aerosol processing. However, the parameterization is intended to account for the aerosol processing that occurs as the plume dilutes to the size of the model grid cell. So long as the spatial resolution of the cloud or large-eddy simulation is sufficiently coarse that $F$ would asymptote before the plume dilutes to the spatial scale of the model, the temporal resolution of the model should not greatly affect the predicted value of $F$, even if it is less than the time required for the plume to dilute to the spatial scale of the model. If the model has a finer spatial resolution, then $F$ may be underestimated if the parameterization is used (both the parameterization and the resolved coagulation in the plume would each reduce $F$ ).

\section{Global model experiment design and results}

In order to assess the effect of the parameterization on predictions of marine cloud brightening efficacy, we did three $5 \mathrm{yr}$ global simulations using the ECHAM-HAMMOZ model (Sect. 2.3) with an additional $1 \mathrm{yr}$ spin-up period. The model was run with horizontal resolution T63 (corresponding roughly to $1.9^{\circ} \times 1.9^{\circ}$ grid), 31 vertical layers extending
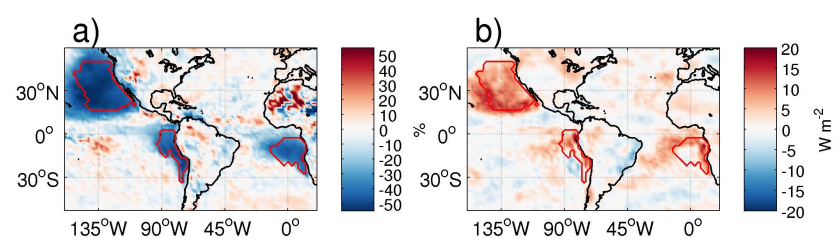

Fig. 6. (a) The relative difference in $5 \mathrm{yr}$ mean cloud-top cloud droplet number concentration between simulations geo-coag and geo-ref. (b) $5 \mathrm{yr}$ mean radiative flux perturbation between simulations geo-coag and geo-ref. Red values mean larger values in the geo-coag simulation.

to $10 \mathrm{hPa}$, and prescribed climatological sea surface temperatures.

In the control run (ctrl) there was no geoengineering applied. The reference geoengineering simulations (geo-ref) had artificial sea salt injections applied in three stratocumulus regions (indicated by the red lines in Fig. 6) that had been previously assessed as optimal to maximize the radiative effect from geoengineering (Partanen et al., 2012). The injected sea-salt particle number flux $F_{n}$ with $10 \mathrm{~m}$ wind speed of $u$ was set according to the following formula:

$F_{n}=3.1 \times 10^{5} \times\left(\min \left(u, 7 \mathrm{~ms}^{-1}\right)\right)^{1.5} \mathrm{~m}^{-2} \mathrm{~s}^{-1}$.

The mass flux (about 20.6 Tg per year) and the functional form of injection were identical to the simulation GEO described by Partanen et al. (2012), although the number flux was different due to the different particle size. The massmean diameter of the injected particles was set to $200 \mathrm{~nm}$, which, with a mode standard deviation of 1.59 , corresponds 
Table 3. Mean cloud-top cloud droplet number concentration $\left(\mathrm{cm}^{-3}\right)$ averaged over cloudy time steps for the geoengineered regions in North Pacific (NP), South Pacific (SP), and South Atlantic (SA) as shown in Fig. 6.

\begin{tabular}{lccc}
\hline Simulation & NP & SP & SA \\
\hline ctrl & 103 & 131 & 166 \\
geo-ref & 607 & 624 & 754 \\
geo-coag & 302 & 345 & 436 \\
\hline
\end{tabular}

to a number-median diameter of $145 \mathrm{~nm}$ used as input for the parameterization.

The other geoengineering simulation (geo-coag) was identical to geo-ref except that the injected sea-salt number flux and number-median diameter were modified by the subgrid coagulation parameterization. We assumed neutral atmospheric stability for all geoengineered regions during the simulation and a stack radius of $1.2 \mathrm{~m}$. The input number flux to the parameterization used the same wind speed dependence as Eq. (6), and was set to $1.2 \times 10^{17} \mathrm{~s}^{-1}$ (corresponding to sea water flux of $30 \mathrm{~kg} \mathrm{~s}^{-1}$, see Sects. 2.2 and 3) at wind speeds greater than or equal to $7 \mathrm{~m} \mathrm{~s}^{-1}$. As we assumed always neutral atmospheric stability and a fixed size distribution of emitted particles as inputs to the parameterization, the final number and particle diameter after the parameterization depended only on wind speed.

The number flux of injected sea-salt particles was on average $61 \%$ lower, and particle number-median diameter was $40 \%$ higher in geo-coag than in geo-ref. There was substantial spatial and temporal variation as the fraction of remaining particles varied between about $20 \%$ and $60 \%$ (not shown in a figure).

The lower number emissions in geo-coag lead to a notable decrease in cloud droplet number concentration (CDNC). We diagnosed the cloud-top CDNC by calculating the mean value of CDNC in the highest lying grid cell with warm clouds for each time step and grid cell with non-zero cloud cover. Figure 6 a shows the relative difference of cloud-top CDNC between geo-coag and geo-ref. In the North Pacific region, the 5-year-mean cloud-top CDNC was as much as $56 \%$ lower in geo-coag than in geo-ref. Averaging over all the emission regions, the mean change was $-46 \%$. Regional mean values of cloud-top CDNC for the geoengineered regions are given in Table 3. The highest mean CDNC was achieved in geo-ref in the South Atlantic region $\left(754 \mathrm{~cm}^{-3}\right)$. The corresponding value in geo-coag was $42 \%$ lower.

The lower number of aerosol particles and cloud droplets also caused differences in the radiative response. We evaluated the total aerosol radiative effect (both direct and indirect effects) as radiative flux perturbation (RFP) (Haywood et al., 2009), i.e., difference in net total (shortwave and longwave) radiation at the top of the atmosphere between the geoengineering runs and the control simulation. The global
Table 4. Mean radiative flux perturbation $\left(\mathrm{W} \mathrm{m}^{-2}\right)$ for the geoengineered regions in North Pacific (NP), South Pacific (SP), and South Atlantic (SA) as shown in Fig. 6. The last column is the global mean value (GM).

\begin{tabular}{lcccc}
\hline Simulation & NP & SP & SA & GM \\
\hline geo-ref & -31.1 & -30.4 & -29.2 & -1.5 \\
geo-coag & -21.8 & -24.4 & -23.8 & -0.8 \\
\hline
\end{tabular}

mean RFPs (with respect to $c t r l$ ) in geo-ref and geo-coag were $-1.5 \mathrm{~W} \mathrm{~m}^{-2}$ and $-0.8 \mathrm{~W} \mathrm{~m}^{-2}$ respectively. The regional mean RFPs in geo-ref and in geo-coag were about $-30 \mathrm{~W} \mathrm{~m}^{-2}$ and $-20 \mathrm{~W} \mathrm{~m}^{-2}$, respectively (Table 4).

It is noteworthy that the effect of parameterization was greater on the global mean RFP than regional mean RFPs (Table 4). At least a partial explanation for this can been seen in Fig. 6b, which shows the RFP between the simulations geo-coag and geo-ref. Especially in the North Pacific and South Atlantic regions, there were large areas with significant positive RFP between geo-coag and geo-ref outside the emission regions (Fig. 6b). These areas were not included in the regional mean values in Table 4 , but they would contribute to the global mean value. The large positive RFPs outside the emission regions are probably a result of 2-6 percentage points lower total cloud cover in geo-coag compared to geo-ref near the emission regions in North and South Pacific (not shown in a figure). The difference in the cloud cover was lower inside the emission regions.

Thus, we estimate that omission of plume-scale coagulation reduces the efficacy of marine cloud brightening by almost $50 \%$ globally. While we have not yet tested these results in cloud-resolving models, we expect these results to be similar since most of the plume-scale coagulation occurs on spatial scales not resolved by the cloud-resolving models typically used for marine cloud brightening studies.

\section{Conclusions}

In this paper, we have used a multi-shelled Gaussian plume model to determine the fraction of particles remaining after coagulation in the plume of intentional sea-spray injections for marine cloud brightening. We have explored the dependence of this fraction on six meteorological and emission parameters. The fraction of particles remaining was most sensitive to the atmospheric stability, the wind speed and the number emission rate with this fraction varying from over 0.9 to under 0.1 depending on the conditions. The results depend less strongly on the radius of the emission source, the number-median diameter, and the geometric width of the emission size distribution. We do not include the decrease in the wet diameter of the particles during transport due to evaporation or effects on the dynamics of the plume due to evaporative cooling. However, the results of the model are 
not strongly dependent on the wet diameter of the particles, and the results of Jenkins and Forster (2013) suggest that the effects of evaporative cooling on the dynamics of the plume would not strongly affect our results.

We have fit our results to a parameterization that depends on the six parameters using a semi-empirical formula based on Turco and Yu (1997). This parameterization can be applied to point source emissions of aerosol generally, such as small combustion sources. The parameterization has a meansquared error in the fraction of particles remaining of 0.05 for very unstable conditions and 0.01 for stable conditions, and the correlation coefficients range from 0.964 for very unstable conditions to 0.999 for stable conditions. We provide Fortran code of this parameterization as supplementary material that calculates both the fraction of particles remaining and the final number-median diameter of the distribution.

We have implemented this parameterization into a globalscale aerosol-climate model, and we found that accounting for this subgrid-scale coagulation reduced the number flux of injected particles by $61 \%$, resulting in reductions in CDNC and RFP over source regions of about $46 \%$ and $25 \%$, respectively. The global mean RFP was reduced by $47 \%$.

Previous cloud-resolving and global-scale modeling studies were unable to resolve in-plume coagulation due to coarse spatial resolution. The results of this work show that such studies overestimated the number of injected particles that reach cloud base. Using the parameterization developed in this paper, future studies will be able to account for these effects.

\section{Supplementary material related to this article is available online at http://www.atmos-chem-phys.net/13/ 10385/2013/acp-13-10385-2013-supplement.zip.}

Acknowledgements. We gratefully acknowledge NSERC and the Academy of Finland (projects 140867 and 250348) for funding support and ACEnet for computational support. The ECHAMHAMMOZ model is developed by a consortium composed of ETH Zurich, Max Planck Institut für Meteorologie, Forschungszentrum Jülich, University of Oxford, and the Finnish Meteorological Institute and managed by the Center for Climate Systems Modeling (C2SM) at ETH Zurich.

Edited by: V.-M. Kerminen

\section{References}

Abdul-Razzak, H. and Ghan, S. J.: A parameterization of aerosol activation: 2. multiple aerosol types, J. Geophys. Res., 105, 68376844, doi:10.1029/1999JD901161, 2000.

Albrecht, B.: Aerosols, cloud microphysics, and fractional cloudiness, Science, 245, 1227-1230, 1989.

Alterskjær, K. and Kristjánsson, J. E.: The sign of the radiative forcing from marine cloud brightening depends on both particle size and injection amount, Geophys. Res. Lett., 40, 210-215, doi:10.1029/2012GL054286, 2013.

Alterskjær, K., Kristjánsson, J. E., and Seland, Ø.: Sensitivity to deliberate sea salt seeding of marine clouds -observations and model simulations, Atmos. Chem. Phys., 12, 2795-2807, doi:10.5194/acp-12-2795-2012, 2012.

Bala, G., Caldeira, K., Nemani, R., Cao, L., Ban-Weiss, G., and Shin, H.-J.: Albedo enhancement of marine clouds to counteract global warming: impacts on the hydrological cycle, Clim. Dynam., 37, 915-931, doi:10.1007/s00382-010-0868-1, 2011.

Bower, K., Choularton, T., Latham, J., Sahraei, J., and Salter, S.: Computational assessment of a proposed technique for global warming mitigation via albedo-enhancement of marine stratocumulus clouds, Atmos. Res., 82, 328-336, doi:10.1016/j.atmosres.2005.11.013, 2006.

Dentener, F., Kinne, S., Bond, T., Boucher, O., Cofala, J., Generoso, S., Ginoux, P., Gong, S., Hoelzemann, J. J., Ito, A., Marelli, L., Penner, J. E., Putaud, J.-P., Textor, C., Schulz, M., van der Werf, G. R., and Wilson, J.: Emissions of primary aerosol and precursor gases in the years 2000 and 1750 prescribed data-sets for AeroCom, Atmos. Chem. Phys., 6, 4321-4344, doi:10.5194/acp-64321-2006, 2006.

Forster, P., Ramaswamy, V., Artaxo, P., Berntsen, T., Betts, R., Fahey, D. W., Haywood, J., Lean, J., Lowe, D. C., Myhre, G., Nganga, J., Prinn, R., Raga, G., Schulz, M., and Dorland, R. V.: Changes in Atmospheric Constituents and in Radiative Forcing, in Climate Change 2007: The Physical Science Basis, Contribution of Working Group I to the Fourth Assessment Report of the Intergovernmental Panel on Climate Change, edited by: Miller, H. L., 129-234, Cambridge University Press, Cambridge, UK and New York, NY, USA, 2007.

Fuchs, N. A.: Mechanics of Aerosols, Pergamon, New York, 1964.

Haywood, J., Donner, L., Jones, A., and Golaz, J.-C.: Global indirect radiative forcing caused by aerosols: IPCC (2007) and beyond, in: Clouds in the perturbed climate system: Their relationship to energy balance, atmospheric dynamics, and precipitation, edited by: Heintzenberg, J. and Charlson, R. J., Cambridge: Strüngmann Forum Report, MIT Press, 451-467, 2009.

Heintzenberg, J., Covert, D. C., and van Dingenen, R.: Size distribution and chemical composition of marine aerosols: a compilation and review, Tellus B, 52, 1104-1122, doi:10.3402/tellusb.v52i4.17090, 2000.

Hudischewskyj, A. B. and Seigneur, C.: Mathematical modeling of the chemistry and physics of aerosols in plumes, Envir. Sci. Tech., 23, 413-421, doi:10.1021/es00181a005, 1989.

Jenkins, A. K. L. and Forster, P. M.: The inclusion of water with the injected aerosol reduces the simulated effectiveness of marine cloud brightening, Atmos. Sci. Lett., 14, 164-169, doi:10.1002/asl2.434, 2013.

Jenkins, A. K. L., Forster, P. M., and Jackson, L. S.: The effects of timing and rate of marine cloud brightening aerosol injection on 
albedo changes during the diurnal cycle of marine stratocumulus clouds, Atmos. Chem. Phys., 13, 1659-1673, doi:10.5194/acp13-1659-2013, 2013.

Jones, A., Haywood, J., and Boucher, O.: Climate impacts of geoengineering marine stratocumulus clouds, J. Geophys. Res., 114, D10106, doi:10.1029/2008JD011450, 2009.

Klug, W.: A method for determining diffusion conditions from synoptic observations, Staub-Reinhalt. Luft, 29, 14-20, 1969.

Korhonen, H., Carslaw, K. S., and Romakkaniemi, S.: Enhancement of marine cloud albedo via controlled sea spray injections: a global model study of the influence of emission rates, microphysics and transport, Atmos. Chem. Phys., 10, 4133-4143, doi:10.5194/acp-10-4133-2010, 2010.

Latham, J.: Control of global warming?, Nature, 347, 339-340, 1990.

Latham, J., Bower, K., Choularton, T., Coe, H., Connolly, P., Cooper, G., Craft, T., Foster, J., Gadian, A., Galbraith, L., Iacovides, H., Johnston, D., Launder, B., Leslie, B., Meyer, J., Neukermans, A., Ormond, B., Parkes, B., Rasch, P., Rush, J., Salter, S., Stevenson, T., Wang, H., Wang, Q., and Wood, R.: Marine cloud brightening., Philos. T. Roy. Soc. A, 370, 4217-4262, doi:10.1098/rsta.2012.0086, 2012.

Lazaridis, M., Isukapalli, S. S., and Georgopoulos, P. G.: Modelling of aerosol processes in plumes, Tellus B, 53, 83-93, doi:10.1034/j.1600-0889.2001.01165.x, 2001.

Lewis, E. R. and Schwartz, S. E.: Sea Salt Aerosol Production: Mechanisms, Methods, Measurements and Models: a Critical Review, American Geophysical Union, Washington D.C., 2004.

Lohmann, U. and Hoose, C.: Sensitivity studies of different aerosol indirect effects in mixed-phase clouds, Atmos. Chem. Phys., 9, 8917-8934, doi:10.5194/acp-9-8917-2009, 2009.

Lohman, K., Seigneur, C., Edgerton, E., and Jansen, J.: Modeling mercury in power plant plumes, Envir. Sci. Tech., 40, 38483854, 2006.

Lohmann, U., Stier, P., Hoose, C., Ferrachat, S., Kloster, S., Roeckner, E., and Zhang, J.: Cloud microphysics and aerosol indirect effects in the global climate model ECHAM5-HAM, Atmos. Chem. Phys., 7, 3425-3446, doi:10.5194/acp-7-3425-2007, 2007.

Mahesh, K.: The Interaction of Jets with Crossflow, in: Annu. Rev. Fluid Mech., 45, edited by: Davis, S. H. and Moin, P., 379407, 4139 El Camino Way, PO BOX 10139, PALO ALTO, CA 94303-0897 USA, 2013.

McKay, M., Beckman, R., and Conover, W.: A comparison of three methods for selecting values of input variables in the analysis of output from a computer code, Technometrics, 29, 239-245, 1979.

Muppidi, S. and Mahesh, K.: Study of trajectories of jets in crossflow using direct numerical simulations, J. Fluid Mech., 530, 81$100,2005$.

Partanen, A.-I., Kokkola, H., Romakkaniemi, S., Kerminen, V.-M., Lehtinen, K. E. J., Bergman, T., Arola, A., and Korhonen, H.: Direct and indirect effects of sea spray geoengineering and the role of injected particle size, J. Geophys. Res., 117, D02203, doi:10.1029/2011JD016428, 2012.

Pasquill, F.: The estimation of the dispersion of windborne material, Meteorol. Mag., 90, 33-49, 1961.

Pringle, K. J., Carslaw, K. S., Fan, T., Mann, G. W., Hill, A., Stier, P., Zhang, K., and Tost, H.: A multi-model assessment of the impact of sea spray geoengineering on cloud droplet number, Atmos. Chem. Phys., 12, 11647-11663, doi:10.5194/acp-1211647-2012, 2012.

Rasch, P. J., Latham, J., and Chen, C.-C.: Geoengineering by cloud seeding: influence on sea ice and climate system, Environ. Rese. Lett., 4, 045112, doi:10.1088/1748-9326/4/4/045112, 2009.

Rosa, E. A. and Dietz, T.: Human drivers of national greenhousegas emissions, Nature Clim. Change, 2, 581-586, 2012.

Royal Society: Geoengineering the climate. Science, governance and uncertainty, Royal Society, London, 2009.

Salter, S., Sortino, G., and Latham, J.: Sea-going hardware for the cloud albedo method of reversing global warming., Philos. T. Roy. Soc. A, 366, 3989-4006, doi:10.1098/rsta.2008.0136, 2008.

Seigneur, C., Wu, X., Constantinou, E., Gillespie, P., Bergstrom, R. W., Sykes, I., Venkatram, A., and Karamchandani, P.: Formulation of a second-generation reactive plume and visibility model, JAPCA J. Air Waste Ma., 47, 176-184, 1997.

Seinfeld, J. H. and Pandis, S. N.: Atmospheric Chemistry and Physics: From Air Pollution to Climate Change, 2nd ed., John Wiley and Sons, Inc., Hoboken, New Jersey, 2006.

Skamarock, W. C., Klemp, J. B., Dudhia, J., Gill, D. O., Barker, D. M., Duda, M. G., Huang, X.-Y., Wang, W., and Powers, J. G.: A Description of the Advanced Research WRF Version 3, NCAR Technical Note, NCAR/TN-475+STR, 2008.

Stevens, R. G., Pierce, J. R., Brock, C. A., Reed, M. K., Crawford, J. H., Holloway, J. S., Ryerson, T. B., Huey, L. G., and Nowak, J. B.: Nucleation and growth of sulfate aerosol in coal-fired power plant plumes: sensitivity to background aerosol and meteorology, Atmos. Chem. Phys., 12, 189-206, doi:10.5194/acp12-189-2012, 2012.

Stier, P., Feichter, J., Kinne, S., Kloster, S., Vignati, E., Wilson, J., Ganzeveld, L., Tegen, I., Werner, M., Balkanski, Y., Schulz, M., Boucher, O., Minikin, A., and Petzold, A.: The aerosol-climate model ECHAM5-HAM, Atmos. Chem. Phys., 5, 1125-1156, doi:10.5194/acp-5-1125-2005, 2005.

Tu, C.-X. and Liu, S.: Nanoparticle coagulation and dispersion in a turbulent planar jet with constraints, Therm. Sci., 16, 1497-1501, 2012.

Turco, R. and Yu, F.: Aerosol invariance in expanding coagulating plumes, Geophys. Res. Lett., 24, 1223-1226, 1997.

Twomey, S.: Pollution and planetary albedo, Atmos. Environ., 8, 1251-1256, doi:10.1016/0004-6981(74)90004-3, 1974.

Vignati, E., Wilson, J., and Stier, P.: M7: An efficient size-resolved aerosol microphysics module for large-scale aerosol transport models, J. Geophys. Res, 109, D22202, doi:10.1029/2003JD004485, 2004.

Wang, H., Skamarock, W. C., and Feingold, G.: Evaluation of Scalar Advection Schemes in the Advanced Research WRF Model Using Large-Eddy Simulations of AerosolCloud Interactions, Mon. Weather Rev., 137, 2547-2558, doi:10.1175/2009MWR2820.1, 2009.

Wang, H., Rasch, P. J., and Feingold, G.: Manipulating marine stratocumulus cloud amount and albedo: a process-modelling study of aerosol-cloud-precipitation interactions in response to injection of cloud condensation nuclei, Atmos. Chem. Phys., 11, 4237-4249, doi:10.5194/acp-11-4237-2011, 2011.

Wen, F., Kamalu, N., Chung, J., Crowe, C., and Troutt, T.: Particle Dispersion by Vortex Structures in Plane Mixing Layers, J. Fluid Eng., 114, 657, 1992. 
Zaveri, R. A., Easter, R. C., Fast, J. D., and Peters, L. K.: Model for Simulating Aerosol Interactions and Chemistry (MOSAIC), J. Geophys. Res., 113, D13204, doi:10.1029/2007jd008782, 2008.
Zhang, K., O’Donnell, D., Kazil, J., Stier, P., Kinne, S., Lohmann, U., Ferrachat, S., Croft, B., Quaas, J., Wan, H., Rast, S., and Feichter, J.: The global aerosol-climate model ECHAM-HAM, version 2: sensitivity to improvements in process representations, Atmos. Chem. Phys., 12, 8911-8949, doi:10.5194/acp-12-89112012, 2012. 